\section{Cobalt cardiomyopathy in a patient on maintenance haemodialysis}

Cobalt has been incriminated in cardiomyopathies in Quebec beer drinkers, ${ }^{1}$ a person exposed to industrial cobalt, ${ }^{2}$ and in patients on maintenance haemodialysis with $^{3}$ and without ${ }^{4}$ cobalt therapy. We report a case of cardiomyopathy in a 17 -year-old girl on maintenance haemodialysis who was given cobalt.

\section{Case report}

Membranoproliferative glomerulonephritis was diagnosed in this patient in 1969 when aged 9 and haemodialysis was started in 1974. She had intermittent hypertension from 1973 to 1976 . Bilateral nephroureterectomy was performed in 1976 because of hypertension and ureteric reflux. From 1975 she had recurrent attacks of severe symptomatic anaemia which, despite iron and folic acid therapy, required frequent transfusions, causing fluid overload.

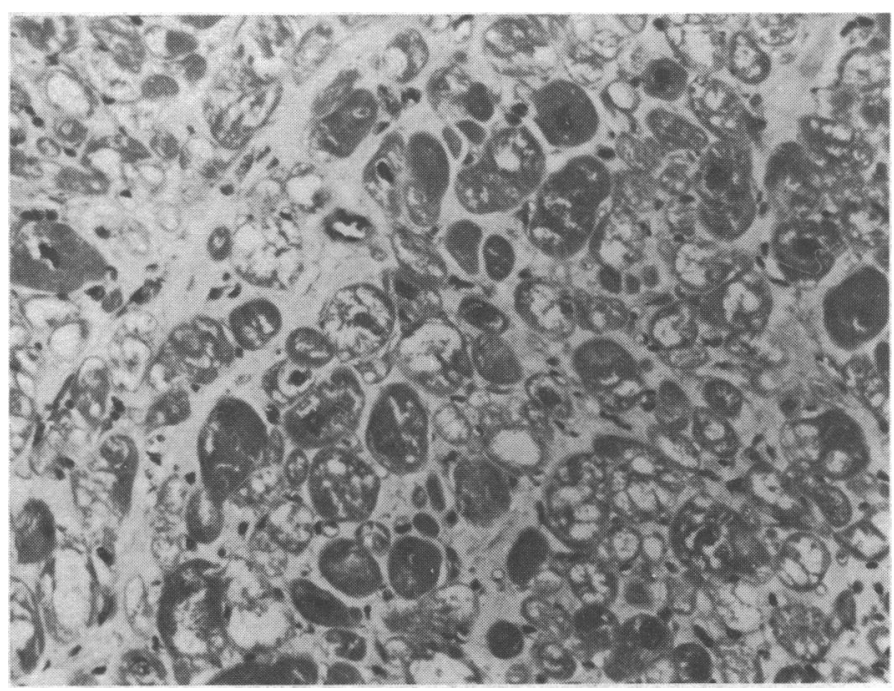

Photomicrograph showing an area of myocardial necrosis. (Haematoxylin and eosin. $\times$ 124.)

Cobaltous chloride $25 \mathrm{mg}$ twice daily was given from August 1976 to April 1977 for the anaemia. In April 1977 she presented with dyspnoea and intermittent central chest pain. She was hypotensive and had raised venous pressure, gallop rhythm, and varying cardiac arrhythmias (supraventricular tachycardia and atrial fibrillation). A severe hyperkalaemia was probably due to the acidosis of poor tissue perfusion. Chest radiography showed globular cardiomegaly, and echocardiography indicated a moderate pericardial effusion and poor left ventricular contraction. Deterioration was rapid and intractable. In a situation of low cardiac output, raised venous pressure, hyperkalaemia, and haemodialysis a haemorrhagic pericardial effusion had to be excluded urgently. A pericardial window was fashioned at operation. Only 0.21 of straw-coloured pericardial fluid was obtained. There was cardiomegaly and a pale myocardium with feeble contractions. Contractions did not improve after excision of part of the pericardium. The patient died a few days later from intractable biventricular failure.

Necropsy showed gross cardiac dilatation. The valves were normal and the coronary arteries had no atheroma. The myocardium looked strikingly unusual to the naked eye, with discrete pale patches due to subepicardial necrosis, quite unlike that seen in diffuse ischaemia. There was no histological evidence of pericarditis and muscle fibres were separated by fibrous tissue with relatively few inflammatory cells. The fibres were vacuolated with loss of striations and irregular, very large nuclei (figure). Some fibres contained PAS-positive granules. Stains for amylase and lipopolysaccharide deposition were negative. These changes were similar to those reported in men exposed to cobalt and also in experimental animals. ${ }^{5}$ Assay of cobalt in necropsy specimens of myocardium by neutron activation analysis showed 8.9 parts per million (dried tissue). This is similar to concentrations found in other cases of cobalt exposure in maintenance dialysis. A "normal" value has been quoted as about 0.2 parts per million. ${ }^{3}$

\section{Comment}

The absence of gross pericardial effusion in this case, in contrast to the beer drinkers, may merely reflect the effect of haemodialysis on removal of fluid. The altered metabolism and nutrition of the dialysed subject may have rendered the myocardium more sensitive to cobalt toxicity. Experimental animals can be protected from cobalt toxicity by feeding high protein diets rich in SH-containing amino-acids. Nevertheless, the evidence in this case points to cobalt as the primary cause of the cardiomyopathy.

We thank Mr J Herrington, of the Atomic Weapons Research Establishment, Aldermaston, for cobalt analyses.

1 Morin, Y L, et al, Canadian Medical Association fournal, 1967, 97, 881.

2 Barborik, M, and Dusek, J, British Heart fournal, 1972, 34, 113.

${ }^{3}$ Curtis, J R, et al, Clinical Nephrology, 1976, 2, 61.

${ }^{4}$ Pehrsson, K, and Lins, L E, Lancet, 1978, 2, 51.

${ }^{5}$ Olsen, E G J, Postgraduate Medical fournal, 1972, 48, 760.

(Accepted 3 October 1978)

Department of Medicine, The Hallamshire Hospital, Sheffield

I $H$ MANIFOLD, $M R C P$, registrar in medicine

$M$ M PLATTS, MD, FRCP, reader in medicine

Northern General Hospital, Sheffield

A KENNEDY, MD, MRCPATH, consultant pathologist

\section{Value of oblique tomography in tracheal stenosis due to retrosternal goitre}

Some time ago a patient with retrosternal goitre presented with stridor to our surgical department. Anteroposterior and lateral tomograms showed a normal calibre trachea, but severe stenosis of the trachea was found at operation. It was suggested that we should try oblique-view tomography in future problem cases. Since then we have collected three such cases. A computer search failed to show any reference to the use of oblique tomography in such cases.

\section{Case 1}

A 56-year-old woman presented with several years' history of swelling in the neck with a recent onset of difficulty in breathing. She was obese and had a goitre with retrosternal extension. Routine views showed no tracheal compression. She was advised to lose weight. Twelve months later she was again seen with noisy breathing. She had a definite stridor. Anteroposterior and lateral tomograms were again normal. Left oblique tomography showed pronounced narrowing of the trachea (see figure). This was confirmed at operation for a benign nodular goitre.

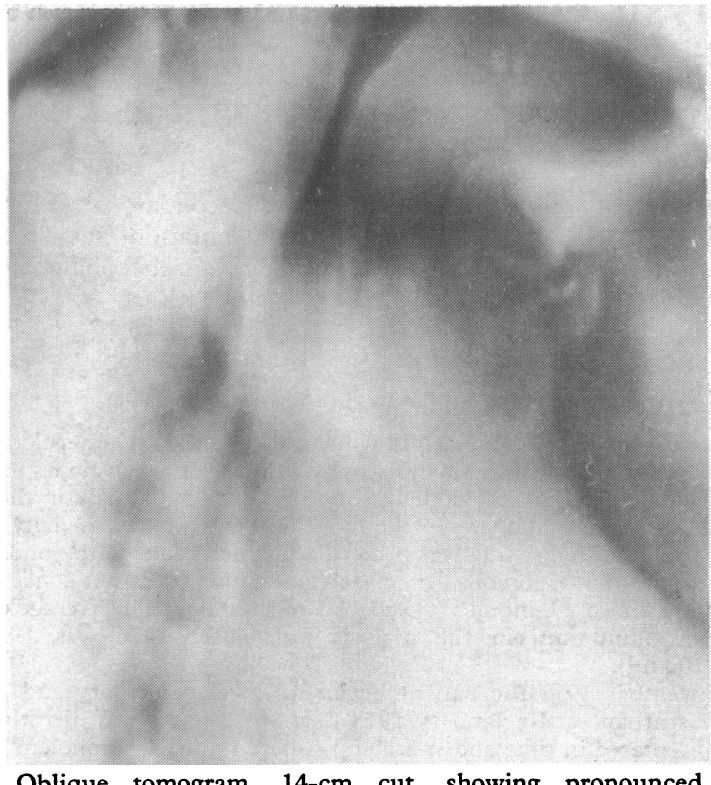

Oblique tomogram, 14-cm cut, showing pronounced narrowing of trachea. 
Case 2

A 50-year-old woman presented with a long history of swelling in the neck. She had a large goitre and signs suggestive of tracheal obstruction. Radiographs of the thoracic inlet showed a superior mediastinal mass pushing the trachea to the left, but with no compression. Anteroposterior and lateral tomograms were normal. Oblique tomograms, however, showed severe narrowing. This was confirmed at operation.

\section{Case 3}

A 65-year-old man presented with a mid-line thyroid swelling. $\mathrm{He}$ had a thyroid nodule removed, which on histology proved to be a papillary carcinoma. At reoperation total thyroidectomy was found to be impossible. He was then treated by radioiodine ablation. Four years later he was seen with a fixed mass in the neck. Radiographs taken at the time showed a retrosternal mass extending down from the neck to the pericardium. An increase in his thyroxine to $0.4 \mathrm{mg} /$ day caused regression of his thyroid swelling. Two years later his thyroid swelling again got larger and he developed a slight stridor. Anteroposterior and lateral tomograms were found to be normal. Nevertheless, left oblique tomograms confirmed the presence of severe tracheal narrowing retrosternally and hence a palliative operation was performed and the severe narrowing confirmed.

\section{Comment}

To show a tracheal stenosis the $x$-ray beam should be in the same plane as the stricture. If the $x$-ray beam is directed at any angle other than to the plane of stricture then the stricture will not be shown on the film. In anteroposterior and lateral films the width of the air column remains unchanged but the degree of blackening is reduced because the $x$ rays traverse only a small column of air. The normal air column gives rise to the misleading conclusion that no stricture is present. In fact a review of the anteroposterior and lateral tomograms did show a loss of blackening of the tracheal air column over the length of the stricture in all our cases.

We therefore suggest that in patients with clinical tracheal obstruction and normal anteroposterior and lateral tomograms oblique views should be used.

We thank Dr N A Lewtas and Mr C H Talbot who first suggested the use of oblique tomography and Christine Hackney for secretarial help.

(Accepted 13 October 1978)

\section{Dialysis encephalopathy : recovery after interruption of aluminium intake}

The course of dialysis encephalopathy secondary to aluminium toxicity is usually fatal, ${ }^{12}$ though transplantation has sometimes averted death. We report here a case of dialysis encephalopathy that was reversed after aluminium intake was stopped.

\section{Case report}

From 1973 to 1977 a 71 -year-old woman with chronic glomerulonephritis received maintenance haemodialysis twice a week for seven hours at a time (RP 5 Cupruphane $/ \mathrm{m}^{2}$ haemodialyser). At the start of dialysis the blood phosphorus concentration was $2.9 \mathrm{mmol} / 1(9.0 \mathrm{mg} / 100 \mathrm{ml})$. A daily dose of $5 \mathrm{~g}$ of aluminium hydroxide was prescribed, which reduced the phosphorus concentration to $1.45 \mathrm{mmol} / 1(4.5 \mathrm{mg} / 100 \mathrm{ml})$; blood calcium concentration varied from 2.4 to $2.8 \mathrm{mmol} / 1(9.5$ to $11.5 \mathrm{mg} / 100 \mathrm{ml})$. The average concentration of aluminium in the dialysis fluid after 1976 was $1.8 \mu \mathrm{mol} / \mathrm{l}$ $(4.9 \mu \mathrm{g} / 100 \mathrm{ml})$.

In November 1977 the patient began to develop memory and psychological disturbances. By January 1978 fixation memory was disturbed; she was disorientated in time and space and suffered diurnal somnolence of one to two hours a day, intermittent myoclonic jerks in the arms and legs, and paroxysmal dysarthria. She also had difficulty with mental synthesis and in maintaining attention. No aphasia, difficulty with comprehension, or other focal signs were found. Neurological examination showed brisk reflexes in all four limbs, plantar reflex in flexion bilaterally, and no focal signs. The electroencephalogram (EEG) showed a disturbed pattern (see figure). The blood calcium concentration was $2.5 \mathrm{mmol} / 1(10.0 \mathrm{mg} / 100 \mathrm{ml})$, phosphorus concentration $1.45 \mathrm{mmol} / 1(4.5 \mathrm{mg} / 100 \mathrm{ml})$, and aluminium concentration $14.8 \mu \mathrm{mol} / 1(40 \mu \mathrm{g} / 100 \mathrm{ml})$. Oral aluminium hydroxide administration was stopped, and the dialysis fluid was replaced by another with a lower aluminium content $(0.3 \mu \mathrm{mol} / 1 \quad(0.8 \mu \mathrm{g} / 100 \mathrm{ml}))$. Haemodialysis was performed three times a week for four hours at a time (RP 6 polyacrylonitrile $/ \mathrm{m}^{2}$ haemodialyser)

One month after aluminium intake was interrupted the dysarthria and the myoclonic jerks disappeared and the patient's psychological state and EEG pattern improved (see figure). The aluminium concentration fell to $3.3 \mu \mathrm{mol} / 1(9 \mu \mathrm{g} / 100 \mathrm{ml})$, and calcium and phosphorus concentrations were $2.4 \mathrm{mmol} / 1(9.6 \mathrm{mg} / 100 \mathrm{ml})$ and $2.4 \mathrm{mmol} / 1(7.4 \mathrm{mg} / 100 \mathrm{ml})$ respectively. By March 1978 all clinical and EEG signs had disappeared and the blood aluminium concentration was $2.5 \mu \mathrm{mol} / 1(6.7 \mu \mathrm{g} / 100 \mathrm{ml})$.

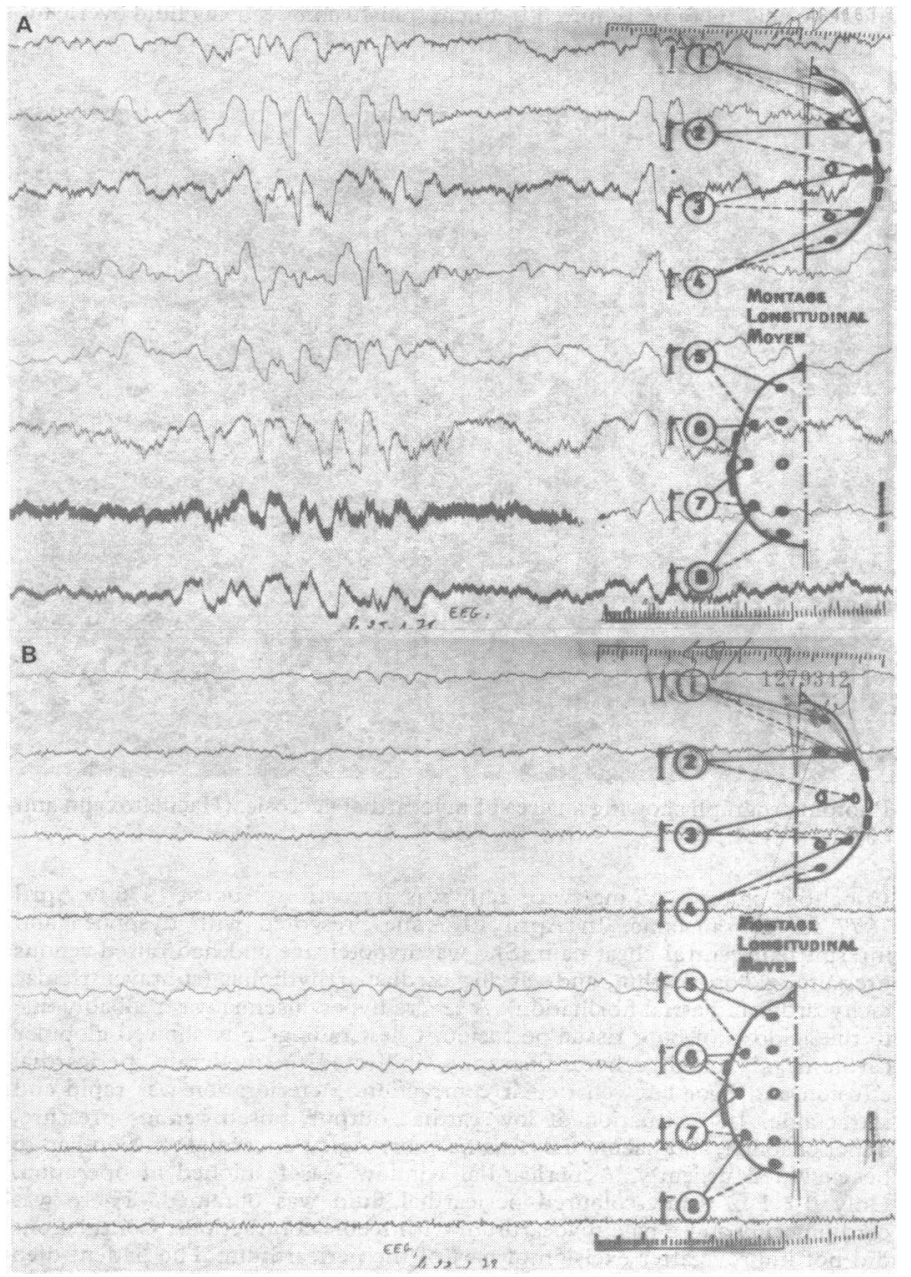

(a) January 1978. EEG showing bilateral synchronous intermittent slow waves. Blood aluminium concentration was $14.8 \mu \mathrm{mol} / 1(40 \mu \mathrm{g} / 100 \mathrm{ml})$. (b) February 1978. Normal EEG. Blood aluminium concentration was $3 \cdot 3 \mu \mathrm{mol} / 1(9 \cdot 0 \mu \mathrm{g} / 100 \mathrm{ml})$.

\section{Comment}

Although dialysis encephalopathy due to aluminium toxicity is usually fatal, ${ }^{12}$ cases that were reversed after aluminium administration was stopped have been reported. ${ }^{4}$ In these cases the encephalopathy began to regress a few weeks, or rarely a few months, after the interruption of aluminium intake; clinical signs were moderate; the EEG pattern was disturbed only after hyperpnoea; and the aluminium concentration was generally under $11 \cdot 1 \mu \mathrm{mol} / \mathrm{l}(30 \mu \mathrm{g} / 100 \mathrm{ml})$. Nevertheless, the relation between the degree of clinical disturbance and the aluminium concentration is not absolute.

Three features in our patient suggested that aluminium toxicity was the cause of the encephalopathy. Firstly, the clinical and EEG signs were identical to those found in other cases of dialysis encephalopathy due to aluminium intoxication. ${ }^{12}$ Secondly, the blood 